\title{
Research on Dual-Loop Grid Connected Inverter to Suddenly Changeable Load
}

\author{
Chengxin Xu \\ Chengdu University of Information Technology, Chengdu, 610225, China \\ Email:xcx@cuit.edu.cn
}

Keywords: voltage outside loop, current inside loop, grid-connected inverter, changeable load, PSCAD/EMTDC

\begin{abstract}
With the development of society, there are new demands for the generate methods and the restriction for the impact on the environment. To improve the traditional centralized power generation pollution and low efficiency problems, the distributed generation has been presented. Although distributed power supply has various forms, when they cut-in the grid, they must use grid-connected inverters. The traditional inverter consumes large reactive power and produce harmonic seriously, causing the adverse effects on the grid. In recent years, the based on voltage external loop and current internal loop dual-loop grid-connected inverter gradually developed, in this paper we built the micro grid simulation model based on this kind of inverter in PSCAD/EMTDC and we configure the artificial settings to produce external load changes, and we discuss the parameters changes in the process. The results show that the inverter has good dynamic effect and prominent regulation effect.
\end{abstract}

\section{Introduction}

With the development of industrial society, because the electricity power is a convenient energy, it plays a more and more important role in the industry production and people life. But except benefit the people to use electric energy conveniently, the power system at present is also facing lots of problems ${ }^{[1]}$. The first one is when the traditional fossil fuel is burnt to generate power, it will produce harmful gases and has greatly adverse influences on environment, and fossil energy is nonrenewable energy, it will run out in the decades. In addition, with the advanced of the urbanization process, in the power grid, the load points are also rapidly growing, considered from the traditional grid method, to meet the local demand for electricity in some areas, it need to start the a number of construction with power facilities and power grid connection, in this way it may be difficult to adapt to the distributed load in a large areas in the future ${ }^{[2]}$. Therefore, in order to solve these problems, the electricity workers have tried some pioneering attempts; the distribution generation is a good solution. The biggest difference with the traditional grid is the power devices are arranged near the customer distribution network or directly install in the vicinity to the houses, although its power capacity is small, the voltage level is not high, but it has a outstanding flexibility to meet the user's demand for electricity, and the line protection and insulation requirements are relatively low, so it has very good prospects for development ${ }^{[3]}$.

Although distributed power sources are various such as wind energy, solar energy, hydrogen, micro turbine and other forms, in the grid the all will still need through the inverters cut-in the grid ${ }^{[4]}$. So it is necessary to do more study and research for improving inverter function.

\section{The principle analysis for the dual-loop inverter}

The traditional inverter usually only uses current feedback or voltage feedback, which is a single loop control system and can only meet the few requirements, at the same time, it will produce the much harmonic component ${ }^{[5]}$. This model uses the dual-loop control system. Voltage external loop for the power factor control and the current internal loop for the current dynamic tracking. The decoupling control structure is shown in figure 1. 


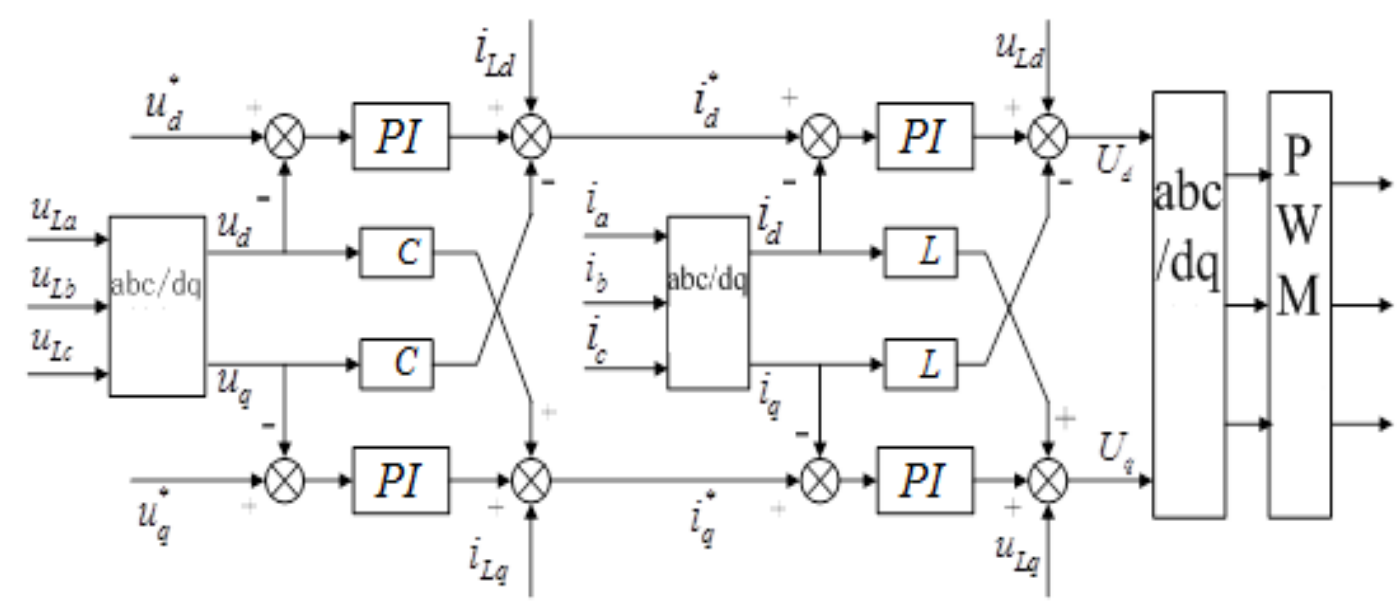

Figure 1. The flow diagram dual-loop control model

The current and voltage decoupling control expression as follows.

$$
\begin{array}{r}
\mathrm{L} \frac{d i_{d}}{d t}+R i_{d}=k_{p}\left(i_{d}^{\prime}-i_{d}\right)+k_{i}\left(i_{d}^{\prime}-i_{d}\right) \mathrm{dt} \\
\mathrm{L} \frac{d i_{q}}{d t}+R i_{q}=k_{p}\left(i_{q}^{\prime}{ }_{q} i_{d}\right)+k_{i}\left(i_{q}^{\prime}-i_{d}\right) \mathrm{dt} \\
\mathrm{C} \frac{d V_{d}}{d t}+R V_{d}=k_{p}\left(v_{d}^{\prime}-v_{d}\right)+k_{i}\left(v_{d}^{\prime}-v_{d}\right) \mathrm{dt} \\
\mathrm{C} \frac{d V_{q}}{d t}+R V_{q}=k_{p}\left(v_{q}^{\prime}-v_{q}\right)+k_{i}\left(v_{q}^{\prime}-v_{q}\right) \mathrm{dt}
\end{array}
$$

According to the related research conclusions and empirical data, we usually set $\mathrm{Kp}=16.455$, $\mathrm{Ki}=118000$.

\section{Simulation and wave forms}

The simulation models in the PSCAD is shown in Figure 2, the dual-loop control model is shown in Figure 3, The micro-grid voltage class is $400 \mathrm{kV}$, rated capacity of $2 \mathrm{MVA}$.To study the situation for the inverter work on changing load in grid, setting circuit breaker in the basic load in $3 \mathrm{~S}$ first put $0.2 \mathrm{MW}+0.1 \mathrm{MVar}$ load, then cut the load in the $7 \mathrm{~s}$.

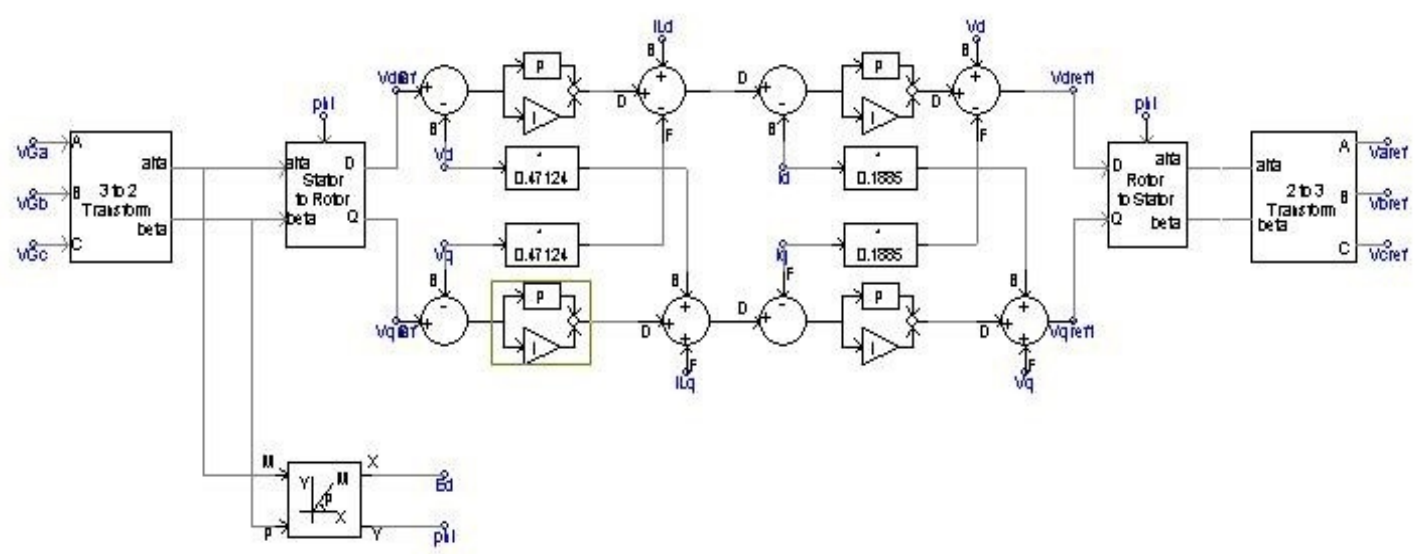

Figure 2. Dual-loop control module model 


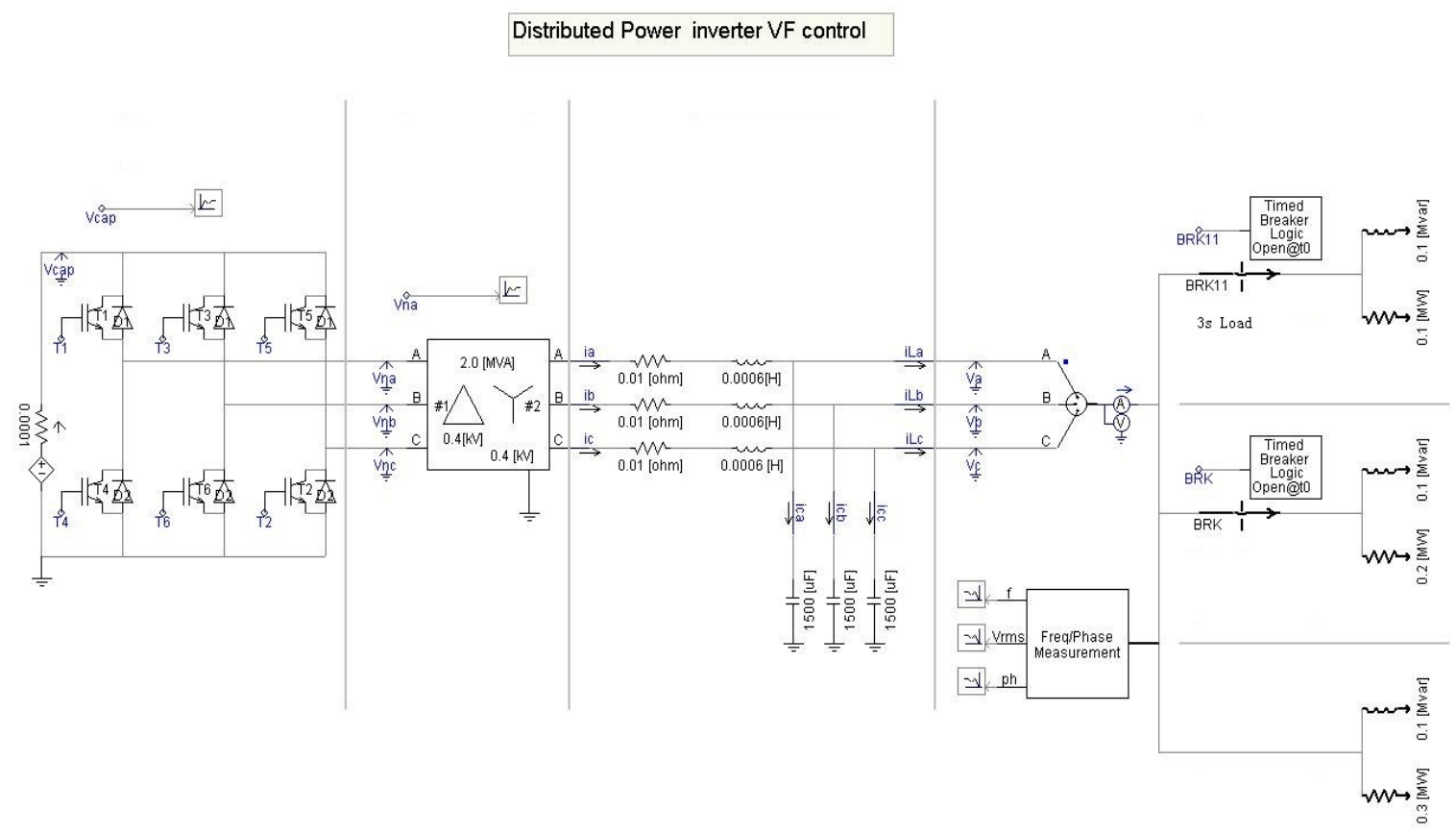

Figure 3. The micro-grid simulation model

In contrast, we measured the voltage waveform take, power frequency and voltage per unit value of no-load and changeable load, the waveform is as follow:

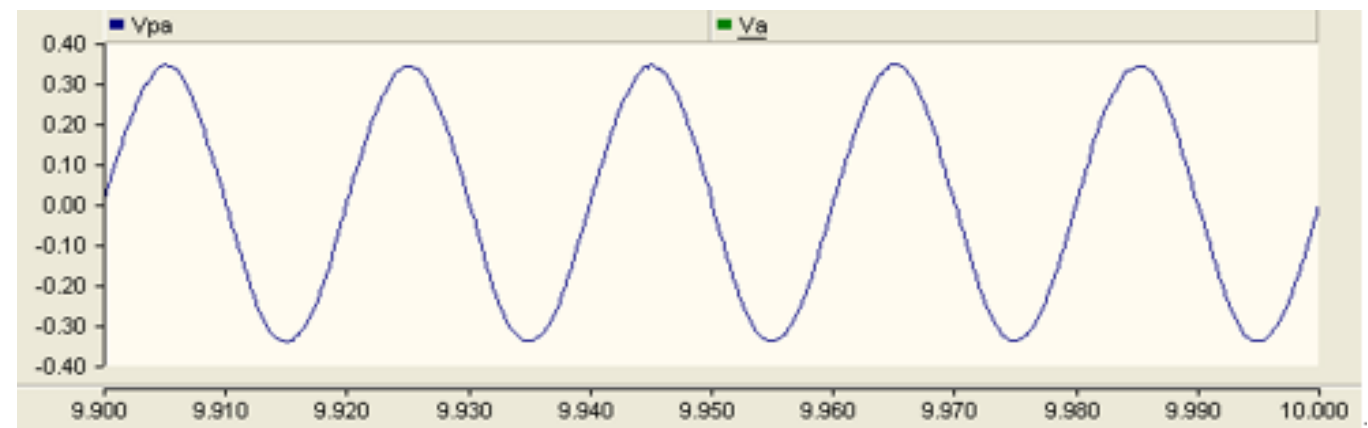

(A) voltage wave

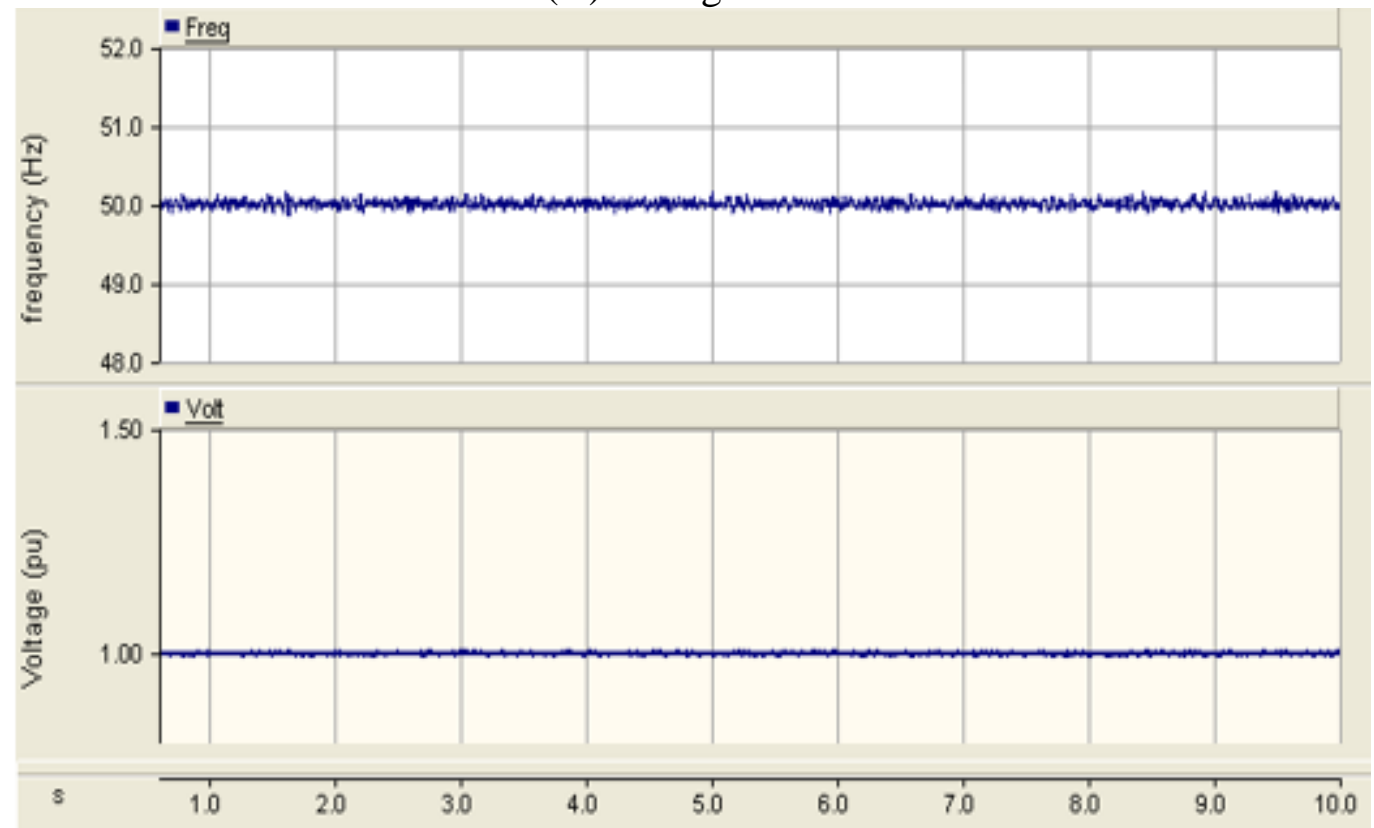

(B) power frequency and voltage per unit value

Figure 4. The simulation result for the no-load (A phase) 


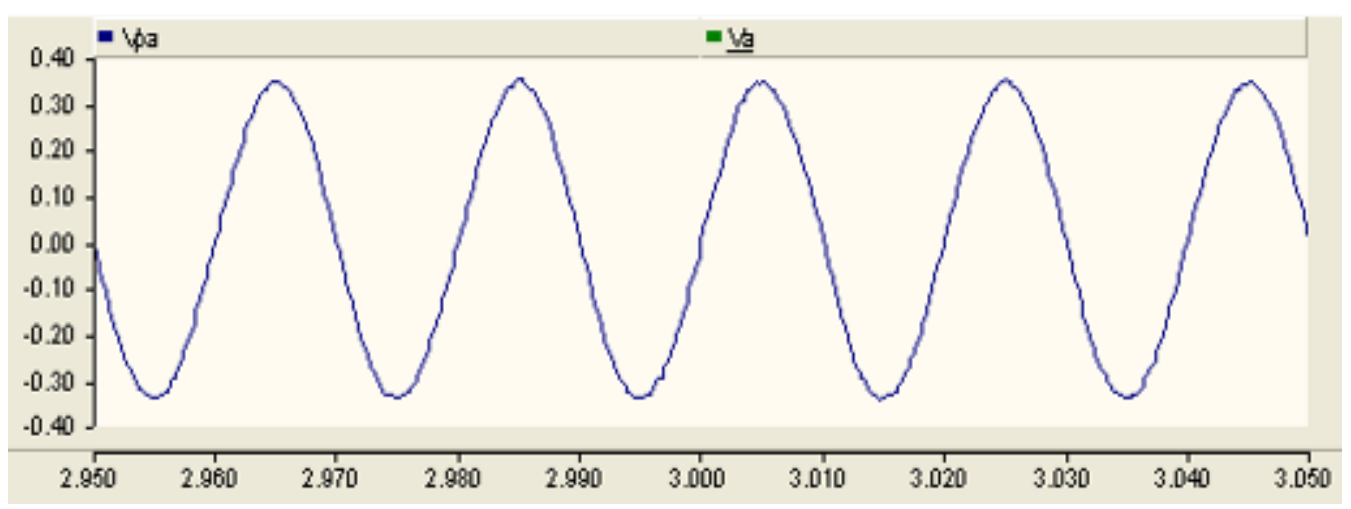

(A) voltage wave (3s)

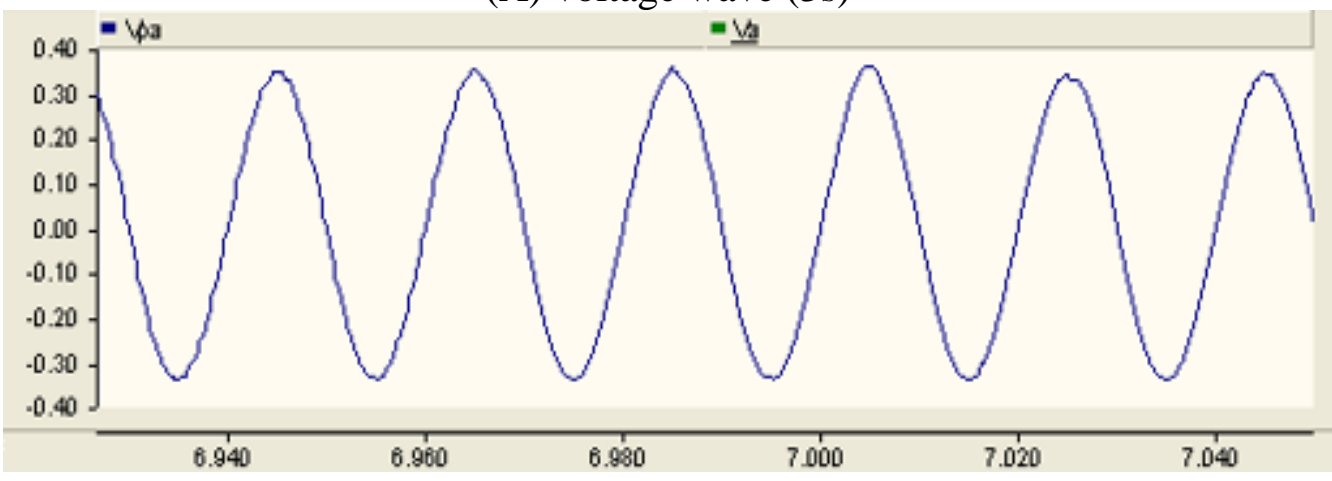

(B) voltage wave (7s)

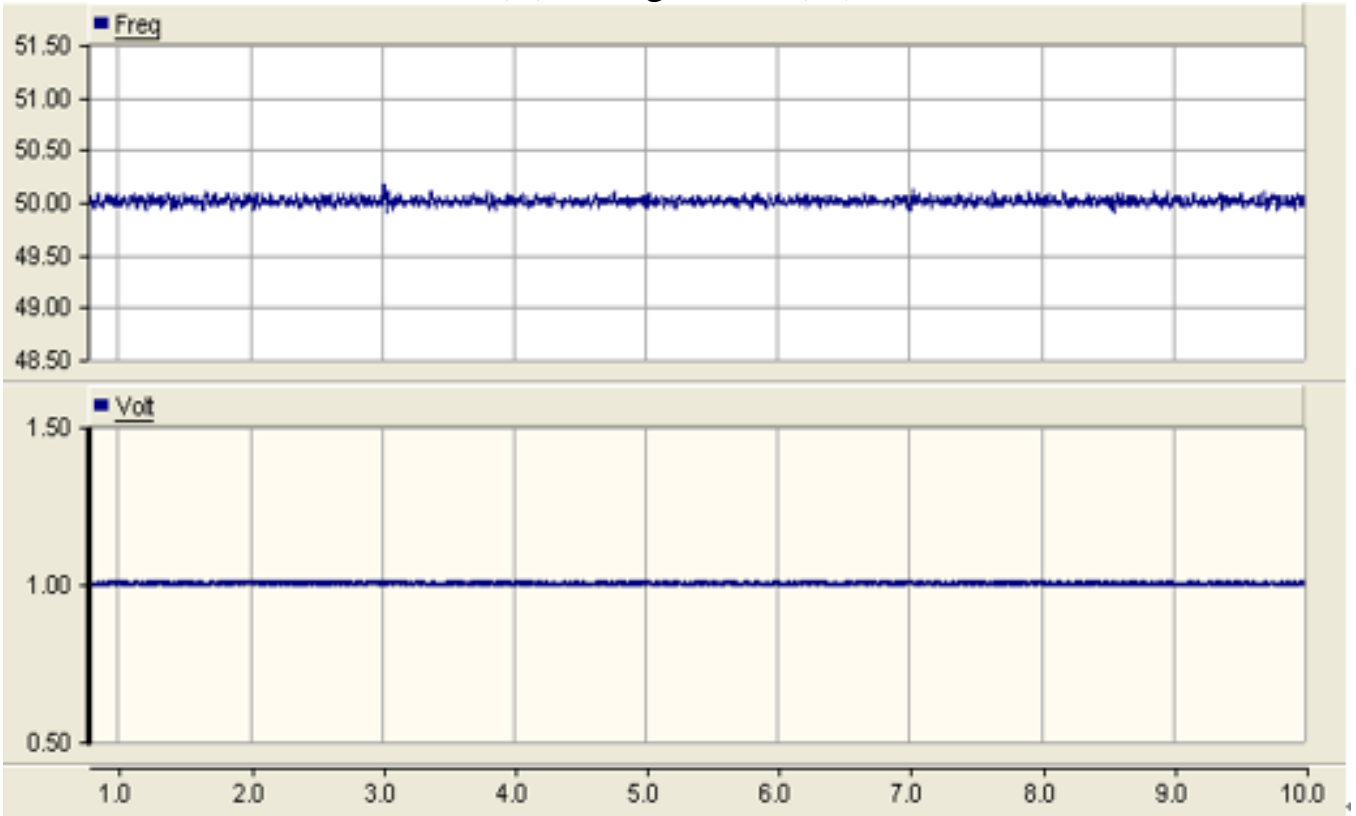

(C) power frequency and voltage per unit value

Figure 5. The simulation results for the changeable load

\section{Conclusion}

The no-load voltage waveform is shown in Figure 4 (A), it is the ideal sinusoidal waveform, from the diagram (B) waveform can be observed voltage per unit value range $<0.01$, frequency change $<0.1 \mathrm{~Hz}$, during the whole process although there are small fluctuations, it is in the acceptable range and the overall change is smooth. While in the sudden load situation, at 3s, $0.2 \mathrm{MW}+0.1 \mathrm{Mvar}$ load increased, at $7 \mathrm{~s}$ when the load is cut out, during the whole process we can see the voltage waveform has slightly shock, but not have suddenly obvious change, the overall performance is still close to the ideal sinusoidal waveform, voltage per unit change $<0.01$, frequency 
change $<0.12 \mathrm{~Hz}$, it is still in the allowed range. Thus we can think dual-loop grid-connected inverter has good dynamic performance and the regulate effort.

\section{References}

[1] Gene F Franklin, J. David Powell, Abbas Emami- Naeini. Feedback control of dynamic systems. 2004

[2] Luiz, A. A, Filho, B. C. Minimum reactive power filter design for high powerthree-level converters. 34th Annual Conference of the IEEE Industrial Electronics Society. 2008

[3] D. Grahame Holmes, Thomas. Pulse Width Modulation for Power Converters: Principles and Practice. 2010

[4] Xing, W, Lan, X, Zhilei, et al. Design of LCL filter for wind power inverter. 2010World Non-Grid-Connected Wind Power and Energy Conference. 2010

[5] Mariethoz S, Morari M. Explicit model-predictive control of a PWM inverter with an LCL filter. IEEE Trans, on Industrail Electronics . 2009 